\title{
Hemofilide Yeni Tedavi Seçeneklerinde Hasta ve Hasta Yakını Perspektifi
}

Patient and Parent Perspective on New Treatment Options in Hemophilia Mehmet Can Uğur ${ }^{1}$ iD , Kaan Kavakıı iD

1 Hematoloji Kliniği, Sağlık Bilimleri Üniversitesi, Bozyaka Eğitim ve Araştırma Hastanesi, İzmir/Türkiye 2 Hematoloji Bilim Dalı, Çocuk Sağlı̆̆ı ve Hastalıkları Anabilim Dalı, Ege Üniversitesi Tıp Fakültesi, İzmir/Türkiye

\section{özeT}

AMAÇ: Günümüzde hemofili tedavisinde profilaktik faktör replasmanı haftada 2 veya 3 kez intravenöz infüzyon yoluyla uygulanmaktadır. Son yıllarda dünyada kullanıma giren, ülkemizde de rutin uygulamaya girmesi beklenen farklı tedavi seçenekleri gündemdedir. Bunlar, yarı ömrü uzatılmış Faktör VIII ve Faktör IX preperatları (EHL); Concizumab, Emicizumab ve Fitusiran gibi subkütan uygulanan tedaviler ve gen tedavisidir. Bu çalışmada hemofili hastaları ve ailelerinin yeni tedavi seçeneklerine bakış açısı, onlardan beklentileri ve çekincelerinin araştırılması amaçlanmıştır.

GEREÇ VE YÖNTEM: Hasta ve ebeveynlerine yüz yüze görüşme yöntemiyle tarafımızca geliştirilen "Hemofilide Yeni Tedaviler Anketi" uygulandı. Elde edilen veriler; hasta ve ebeveyn olarak ayrılan 2 alt grupta, kesitsel olarak değerlendirildi.

BULGULAR: 32 hasta ve 29 ebeveynden oluşan toplam 61 kişiye anket uygulandı. Hemofili hastaları ve ebeveynlere EHL faktörler hakkındaki tercihleri sorulduğunda, hemofiliklerin 31'i (\%96,8), ebeveynlerin 27'si (93,1) evet yanıtını vermiştir ( $p=0,496)$. Subkütan moleküller için hemofiliklerin 27'si (\%84,3), ebeveynlerin tamamı evet yanıtını vermiştir ve istatistiksel olarak anlamlıdır $(p=0,026)$. Gen tedavisi için hemofiliklerin 27'si (\%84,3), ebeveynlerin 26'sı (\%89,6) evet yanıtını vermiştir ( $p=0,542)$. Katılımcılardan yeni tedavi seçeneklerinden birini tercih etmeleri istendiğinde her iki grup da gen tedavisini tercih etmiştir.

SONUÇ: Çalışmada hem hemofilikler, hem de aileleri tarafından en çok tercih edilen tedavi gen tedavisiydi. Subkütan tedaviler ebeveynler, EHL faktörler ise hemofilikler tarafından ikinci sırada tercih edilmekteydi. Tedavi seçeneklerinin tercih edilme nedenleri değerlendirildiğinde, daha az sayıda enjeksiyon olanağı sağlamaları her üç tedavi için de en çok saptanan tercih nedeniydi.

Anahtar Kelimeler: hemofili, emicizumab, fitusiran, concizumab

\section{ABSTRACT}

OBJECTIVE: Today, prophylactic factor replacement with intravenous infusion 2 or 3 times a week is used in the treatment of hemophilia. Different treatment options, which have been used in the world in recent years and are expected to be put into routine practice in our country, are on the agenda. These treatments include Factor VIII and Factor IX preparations with extended half-life (EHL); subcutaneous treatments such as Concizumab, Emicizumab and Fitusiran and gene therapy.In this study, it was aimed to investigate the perspective of hemophilic people and their parents about new treatment options, their expectations and reservations.

MATERIALS AND METHODS: The "New Treatments in Hemophilia Questionnaire" developed by us was applied to the patient and their parents through face-to-face interview method. The data obtained were evaluated cross-sectionally in subgroups of patients and parents.

RESULTS: The questionnaire was applied to a total of 61 people, 32 patients and 29 parents. When hemophilia and parents were asked about their preferences about EHL factors, 31 (96.8\%) of hemophilia and 27 (93.1) of the parents answered yes ( $p=0.496)$. For subcutaneous molecules, 27 (84.3\%) of hemophilia and all parents answered yes and it is statistically significant ( $p=0.026)$. For gene therapy, 27 (84.3\%) of hemophilia and 26 (89.6\%) of the parents answered yes $(p=0.542)$. When the participants were asked to choose one of the new treatment options, both groups preferred gene therapy.

CONCLUSION: In the study, gene therapy was the most preferred treatment by both hemophilic people and their parents. Subcutaneous treatments were preferred by parents and EHL factors by hemophilia. Considering the reasons for preferring treatment options, the most common reason for preference for all three treatments was that they provided fewer injections.

Keywords: hemophilia, emicizumab, fitusiran, concizumab

Yazışma Adresi/Address for Correspondence: Mehmet Can Uğur, MD, Sağlık Bilimleri Üniversitesi, Bozyaka Eğitim ve Araştırma Hastanesi, Hematoloji Kliniği, Karabağlar, İzmir/Türkiye

E-Posta/E-Mail: med.can@hotmail.com || Tel: +905058861126

Received/Geliş Tarihi: 23.05.2021 || Accepted/Kabul Tarihi: 08.10.2021

Bu Eser Creative Commons Atıf-Gayriticari 4.0 Uluslararası Lisansı İle Lisanslanmıştır. This work is licensed under a Creative Commons

Attribution-NonCommercial 4.0 International License (CC BY-NC 4.0). 


\section{Giriş}

Hemofili, 10.000 'de 1 sıklıkta görülen ve X'e bağlı resesif aktarılan genetik bir hastalıktır. Hemofilide, F VIII veya F IX aktivitesindeki eksiklik nedeniyle kanamaya eğilim oluşur. En sık görülen klinik bulgu eklem içi kanamalar olmakla birlikte mukozal hafif kanamalardan iç organların hayatı tehdit eden kanamalarına kadar geniş bir spektrum gözlenebilir $(1,2)$.

Günümüzde hemofili tedavisi, eksik olan koagülasyon faktörünün replasmanı temeline dayanır. Profilaktik tedavi altın standart yaklaşımdır (3). Türkiye'de plazma derive veya rekombinant faktör preperatları kullanılmaktadır. Bu ilaçların yarılanma ömrü Faktör VIII için ortalama 12 saat, Faktör IX için 29 saate kadardır (4). İntravenöz uygulanması da bu ilaçların başka bir önemli özelliğidir. Bu nedenlerle hastalara neredeyse yaşamları boyunca haftada 2-3 kez intravenöz enjeksiyon yapılması gerekmektedir. Son yıllarda gelişmiş ülkelerde klinik çalışmaları devam eden ve kullanıma giren yarı ömrü uzatılmış faktör preperatları (EHL), subkütan yolla uygulanan moleküller ve gen tedavisi gibi non-faktör ilaçlar ise hastaların karşılaştığı bu zorlukları ortadan kaldırma potansiyeline sahipken (5) yıllık kanama sayısında da belirgin düşüş sağlayabilmektedir (6).

EHL faktör VIII ve faktör IX, protein konjugatlarına IgG1'in Fc fragmanı ve albüminin füzyonu veya polietilen glikol (PEG)'in kimyasal modifikasyonu ile elde edilir. Bu tekniklerle faktör IX ürünlerinin yarı ömürlerini 4-6 kat uzatmak mümkünken, faktör VIII ürünlerinin yarı ömründeki artış Willebrand faktörünün yarı ömrüne bağlı olarak 1,5-2 kat ile sınırlıdır. Bu ilaçlarla intravenöz tedavi gerekliliği devam etse de enjeksiyon sıklığını ve kanama sayısını azaltmak mümkün olmuştur (7).

Son yıllarda geliştirilen alternatif farmakolojik tedaviler, faktör replasmanından bağımsız olarak hemostatik potansiyeli artırabilmektedir. Bunlardan en öne çıkanlar, trombin jenerasyonunu sağlamak için koagülasyon kaskadını aktive eden Emicizumab, doğal antikoagülan yolakları inhibe eden Fitusiran ve Concizumab'dır. Subkütan yolla uygulanan bu tedavilerle enjeksiyon sıklığı, moleküle göre değişmekle birlikte günlük, haftalık veya aylık dozlarda olabilir (8). Bu tedavilerin sağladığı en önemli avantajlardan biri hemofilide çok ciddi morbidite ve mortalite nedeni olan allo-antikor varlığında da etkinlik gösterebilmesidir (9).

Bugüne kadar klinik öncesi ve klinik çalışmalarda faktör VIII veya IX hepatosit transdüksiyonu için rekombinant adenoilişkili viral (AAV) vektörleri başarıyla kullanılmıştır. Son klinik veriler, hastalarda faktör düzeylerinin normale yakın seyretmesiyle kanama sayısında azalma ve yaşam kalitesindeki artışı ortaya koymuştur. Bu çalışmalarda görülen temel toksisite, karaciğer enzimlerinde erken ve geçici yükselmelerdir. Uzun dönem veriler beklenmesine rağmen, hemofili köpek modellerinde geç toksisite veya onkogenez görülmemiştir. Ayrıca klinik çalışmalardaki dahil edilme/dışlama kriterleri nedeniyle elde edilen verilerin klinik uygulamaya dönüştürülmesinde sınırlamalar görülebilir (10). Yüksek maliyetli bu tedavi seçeneğinin, Türkiye gibi gelişmekte olan ülkelerde hemofili hastalarının kişiselleştirilmiş tedavisinde adil bir şekilde tercih edilebilmesi için klinik ve finansal sağlık hizmetlerinin geliştirilmesine de intiyaç duyulmaktadır. Bu çalışmada hemofilikler ve ailelerinin yeni tedavi seçeneklerine bakış açısı, onlardan beklentileri ve çekincelerinin araştırılması amaçlanmıştır.

\section{GEREÇ VE YÖNTEM}

Hasta ve ebeveynlerine yüz yüze görüşme yöntemiyle tarafımızca geliştirilen "Hemofilide Yeni Tedaviler Anketi" uygulandı. 18 yaşın üstündeki hemofiliklerin kendisiyle, 18 yaşın altındakilerin ise ebeveynleri ile görüşüldü. Katılımcılara hastalık ve tedavi bilgileri, haftalık enjeksiyon sayısı, hemofilideki yeni tedavi seçenekleri hakkındaki farkındalıkları, bilgi edinme kaynakları, EHL, subkütan tedaviler ve gen tedavisi hakkındaki olumlu veya olumsuz fikirleri soruldu. Elde edilen veriler hasta ve ebeveynler alt gruplarında kesitsel olarak değerlendirildi. Çalışma, İzmir Bozyaka Eğitim ve Araştırma Hastanesi Etik Kurulu tarafından onaylandı.

\section{Istatistik:}

SPSS 21.0 programı kullanılarak Chi-Square testi ile değerlendirildi. $p$ değeri $<0,05$ istatistiksel olarak anlaml kabul edildi.

\section{BULGULAR}

32 hasta ve 29 ebeveyn olmak üzere toplam 61 katılımcıya anket uygulandı. Hemofiliklerin ve ebeveynlerin hemofilik çocuklarının hemofili tipi, inhibitör öyküsü, aldığı tedaviler, faktör ürünleri, profilaktik tedavi alanların haftalık enjeksiyon sayısı, katılımcıların yeni ilaçlar hakkındaki farkındalığı ve bilgi edinme kaynakları Tablo 1'de gösterilmiştir.

Hemofilikler ve ebeveynlere EHL faktörler hakkındaki tercihleri sorulduğunda, hemofiliklerin 31'i evet $(\% 96,8)$, 1'i 
hayır $(\% 3,1)$; ebeveynlerin 27'si evet $(\% 93,1)$, 2'si hayır $(\% 6,8)$ yanıtını vermişsir. Subkütan moleküller hakkındaki tercihleri sorulduğunda, hemofiliklerin 27'si evet $(\% 84,3)$, 5'i hayır $(\% 15,7)$; ebeveynlerin tamamı evet yanıtını vermiştir ve bu fark istatistiksel olarak anlamlıdır $(p=0,026)$. Katılımcıların gen tedavisi hakkındaki tercihleri sorulduğunda, hemofiliklerin 27'si evet (\%84,3), 5'i hayır (\%15,7); ebeveynlerin 26 'sı evet $(\% 89,6), 3$ üü hayır $(\% 10,4)$ yanıtını vermiştir. Hemofilikler ve ebeveynlerin verdikleri evet veya hayır yanıtlarının nedenleri ve gruplar arasındaki istatistiksel fark EHL için Tablo 2'de, subkütan ilaçlar için Tablo 3'de ve gen tedavisi için Tablo 4'de gösterilmiştir.

Katılımcılardan yeni tedavi seçeneklerinden sadece birini tercih etmeleri istendiğinde elde edilen yanıtlar Figür 1'de gösterilmiştir.

Her iki katılımcı grubunda EHL, subkütan ilaçlar veya gen tedavisi tercihlerinin hemofili tipi, inhibitör öyküsü, aldığ tedavi, kullandığı faktör ürünü, haftalık enjeksiyon sayısı, yeni tedaviler hakkındaki farkındalık ve bilgi alma kaynakları arasında istatistiksel anlamlı ilişki saptanmamıştır.

Tablo 1. Katılımcıların tanımlayıcı özellikleri

\begin{tabular}{|c|c|c|c|c|c|}
\hline & & \multicolumn{2}{|c|}{ Hemofilik } & \multicolumn{2}{|c|}{ Ebeveyn } \\
\hline & & $\mathbf{n}$ & $\%$ & $\mathbf{n}$ & $\%$ \\
\hline \multirow{4}{*}{ Hemofili Tipi } & A & 23 & 71.8 & 27 & 93.2 \\
\hline & B & 9 & 28.2 & 2 & 6.8 \\
\hline & Ağır & 27 & 84.3 & 29 & 100.0 \\
\hline & Orta & 5 & 15.7 & 0 & 0.0 \\
\hline \multirow{3}{*}{ İnhibitör } & Şuan var & 1 & 3.1 & 4 & 13.6 \\
\hline & Geçirilmiş & 4 & 12.4 & 1 & 3.4 \\
\hline & Yok & 27 & 84.5 & 24 & 83.0 \\
\hline \multirow{2}{*}{ Tedavi } & Profilaksi & 26 & 81.2 & 28 & 96.6 \\
\hline & Kanadıkça & 6 & 18.8 & 1 & 3.4 \\
\hline \multirow{2}{*}{ Faktör ürünü } & Plazma kaynaklı & 9 & 28.2 & 9 & 31.0 \\
\hline & Rekombinant & 23 & 71.8 & 20 & 69.0 \\
\hline \multirow{3}{*}{ Haftalık enjeksiyon sayısı } & Haftada 1 & 1 & 3.8 & 11 & 39.6 \\
\hline & Haftada 2 & 14 & 53.8 & 10 & 35.4 \\
\hline & Haftada 3 & 11 & 42.4 & 7 & 25.0 \\
\hline \multirow{2}{*}{ Farkındalık } & Var & 30 & 93.8 & 26 & 89.7 \\
\hline & Yok & 2 & 6.2 & 3 & 10.3 \\
\hline \multirow{4}{*}{ Bilgi edinme kaynağı } & Eğitim toplantıları & 13 & 43.3 & 9 & 34.6 \\
\hline & Takip eden hekim & 9 & 30.0 & 11 & 42.4 \\
\hline & İnternet & 7 & 23.4 & 5 & 19.2 \\
\hline & Diğer hemofilikler & 1 & 3.3 & 1 & 3.8 \\
\hline
\end{tabular}

*n: sayı

Tablo 2. Hemofilikler ve ebeveynlerinin EHL faktörler hakkındaki tercihleri

\begin{tabular}{|c|c|c|c|c|c|c|}
\hline & & \multicolumn{2}{|c|}{ Hemofilik } & \multicolumn{2}{|c|}{ Ebeveyn } & \multirow{2}{*}{ p değeri } \\
\hline & & $n$ & $\%$ & $n$ & $\%$ & \\
\hline \multirow{5}{*}{ Evet } & Daha az kanama & 9 & 28.1 & 13 & 44.8 & \multirow{5}{*}{0.185} \\
\hline & Daha az yan etki & 0 & 0.0 & 1 & 3.4 & \\
\hline & Daha az enjeksiyon & 19 & 59.4 & 12 & 41.6 & \\
\hline & Daha az maliyet & 0 & 0.0 & 1 & 3.4 & \\
\hline & Daha fazla aktivite/spor & 3 & 9.4 & 0 & 0.0 & \\
\hline \multirow{3}{*}{ Hayır } & Etkili değil & 0 & 0.0 & 1 & 3.4 & \multirow{3}{*}{0.371} \\
\hline & Yeterli bilgim yok & 0 & 0.0 & 1 & 3.4 & \\
\hline & Daha fazla yan etki & 1 & 3.1 & 0 & 0.0 & \\
\hline
\end{tabular}

$*_{n: \text { sayı }}$

Tablo 3. Hemofilikler ve ebeveynlerinin subkütan ilaçlar hakkındaki tercihleri

\begin{tabular}{|c|c|c|c|c|c|c|}
\hline & & \multicolumn{2}{|c|}{ Hemofilik } & \multicolumn{2}{|c|}{ Ebeveyn } & \multirow{2}{*}{ p değeri } \\
\hline & & $\mathrm{n}$ & $\%$ & $\mathrm{n}$ & $\%$ & \\
\hline \multirow{5}{*}{ Evet } & Daha az kanama & 2 & 6.2 & 15 & 51.8 & \multirow{5}{*}{0.001} \\
\hline & Daha az yan etki & 0 & 0.0 & 1 & 3.4 & \\
\hline & Daha az enjeksiyon & 21 & 65.8 & 13 & 44.8 & \\
\hline & Daha az maliyet & 1 & 3.1 & 0 & 0.0 & \\
\hline & Daha fazla aktivite/spor & 3 & 9.4 & 0 & 0.0 & \\
\hline \multirow{3}{*}{ Hayır } & Etkili değil & 2 & 6.2 & 0 & 0.0 & \multirow{3}{*}{0.177} \\
\hline & Yeterli bilgim yok & 1 & 3.1 & 0 & 0.0 & \\
\hline & Daha fazla yan etki & 2 & 6.2 & 0 & 0.0 & \\
\hline
\end{tabular}


Tablo 4. Hemofilikler ve ebeveynlerinin gen tedavisi hakkındaki tercihleri

\begin{tabular}{|c|c|c|c|c|c|c|}
\hline & & \multicolumn{2}{|c|}{ Hemofilik } & \multicolumn{2}{|c|}{ Ebeveyn } & \multirow{2}{*}{ p değeri } \\
\hline & & $n$ & $\%$ & $n$ & $\%$ & \\
\hline \multirow{5}{*}{ Evet } & Daha az kanama & 2 & 3.1 & 15 & 51.8 & \multirow{5}{*}{0.667} \\
\hline & Daha az yan etki & 0 & 0.0 & 1 & 3.4 & \\
\hline & Tek uygulamayla tedavi & 21 & 65.9 & 13 & 44.8 & \\
\hline & Daha az maliyet & 1 & 3.1 & 0 & 0.0 & \\
\hline & Daha fazla aktivite/spor & 3 & 9.4 & 0 & 0.0 & \\
\hline \multirow{3}{*}{ Hayır } & Etkili değil & 2 & 6.2 & 1 & 3.4 & \multirow{3}{*}{0.103} \\
\hline & Yeterli bilgim yok & 1 & 3.1 & 1 & 3.4 & \\
\hline & Daha fazla yan etki & 2 & 6.2 & 1 & 3.4 & \\
\hline
\end{tabular}

Figür 1. Hemofilikler ve ebeveynlerinin yeni tedavi seçenekleri hakkındaki tercihleri

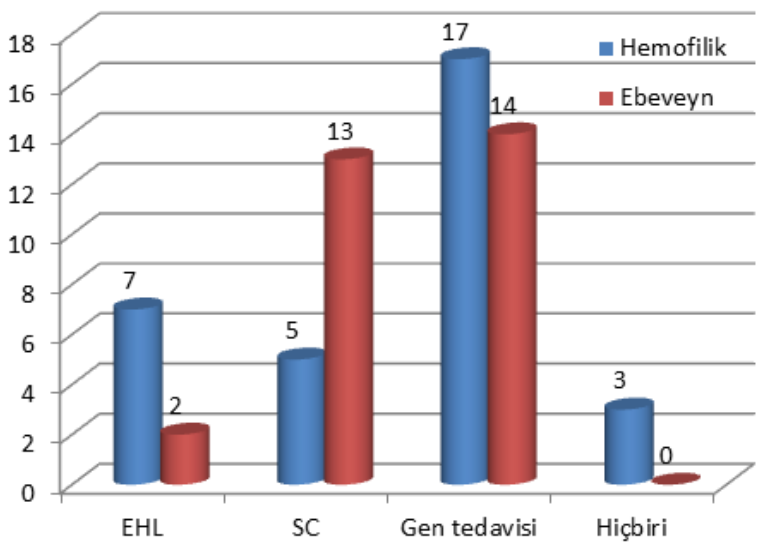

\section{TARTIŞMA}

Günümüzde kullanılan standart faktör ürünleri ile hemofiliklerin profilaksi ve akut kanama tedavileri başarı ile sürdürülebilmektedir. Bu başarıya paralel olarak hemofili hastalarındaki yaşam kalitesi de artmaktadır. Bu nedenle daha az ve daha konforlu enjeksiyon ile daha az kanama vadeden yeni ilaçlar oldukça ilgi çekicidir.

S von Mackensen ve arkadaşlarının 2644 hasta ve yakınına uyguladığı EHL ürünler hakkındaki anket çalışmasında enjeksiyon sıklığındaki azalmanın, etkinlik ve güvenlik nedeniyle tercih nedenlerinin önünde yer aldığı görülmektedir. Bu çalışmada hastaların \%3,2'si, ebeveynlerin ise $\% 5^{\prime i}$ bu ürünleri kullanmayacağını ifade etmiştir (11). Çalışmamızda bu oranlar sırasıyla 3,1 ve 6,8'dir. Ayrıca enjeksiyon sıklığındaki azalmanın önde gelen tercih nedeni olması da literatürle uyumludur. K Steen Carlsson ve arkadaşlarının 1657 erişkin hastada yaptığı çalışmada da enjeksiyon sıklı̆̆ı ve fiziksel aktivite olanağı gibi tedavi özelliklerinin, kanama olaylarının kontrolü ve önlenmesinin yanı sıra yaşam kalitesini etkileyen önemli kazanımlar olduğu gösterilmiştir (12). Van Balen ve arkadaşları ise çalışmalarında enjeksiyon sıklığındaki azalmanın neden ön planda olduğunu ortaya koymuştur. Buna göre enfeksiyon riskinin azalması, enjeksiyon zamanlarının daha kolay planlanması, tedavi ürünlerinin taşınma/saklanma zorunluluğunun ortadan kalkması altta yatan en önemli sonuçlardır (13).

Çalışmamızda subkütan ilaçlara bakış açısı da EHL faktörlere benzerdir. Özellikle inhibitörlü hastaların tedavisinde ön plana çıkması beklenen bu ilaçlarda (14) kanama sayısındaki azalma beklentisi enjeksiyon sıklığının gerisinde kalmıştır. Çalışmada yer alan hasta ve ebeveynlerden inhibitör sorunu yaşayanların sayısının nispeten az olması, bu duruma yol açmış olabilir. Ayrıca von Mackensen'in çalışmasında (11) yeni ilaçlar konusunda ebeveynler, hemofiliklere göre daha tutucu bulunurken; çalışmamızda tüm dünyanın yeni tanımaya başladığı ve klinik çalışmalarında trombotik olaylar gibi ciddi yan etkilerin bildirildiği subkütan ilaçlar hemofiliklere göre ebeveynler tarafından açık ara önde tercih edilmektedir. "Yeterli bilgi sahibi değilim" yanıtının sadece 1 hemofilik katılımcı tarafından verildiği göz önünde bulundurulduğunda, iki çalışma arasındaki bu fark örneklemlerin alındığı ülkelerin (Almanya, İsviçre, Avusturya ve Türkiye) sosyoekonomik farklııılarından kaynaklanabilir.

Çalışmamızda gen tedavisinin katılımcılar tarafından birinci sırada tercih edilmesinin nedeni, tek uygulamayla tedavi olanağı sağlaması olarak saptanmıştır. Ancak dünyadaki sosyoekonomik heterojenite ve sağlığa ayrılan bütçeler, tedavi olanaklarını ve hastaların tercihlerini değiştirebilmektedir. Overbeeke ve arkadaşlarının 117 hasta üstünde gerçekleştirdikleri anket çalışmasında da gen tedavisi için hasta tercihlerinin heterojenliğine ve bu heterojenitenin hasta eğitimleri ile değişebileceğine vurgu yapılmaktadır (15). Önümüzdeki dönemde gen tedavisinin önündeki medikal sorunların yanı sıra hasta tercihlerini etkileyecek en büyük sorun bu durum olabilir $(16,17)$.

\section{SONUÇ}

Hemofili tipi, inhibitör öyküsü, aldığı tedavi, kullandığı faktör ürünü, haftalık enjeksiyon sayısı, yeni tedaviler hakkındaki 
farkındalık ve bilgi alma kaynaklarının hemofilikler ve yakınlarının tedavi seçeneklerine yaklaşımlarında etkili olmadığı saptandı. Hem hemofilikler, hem de yakınları tarafından en çok tercih edilen tedavi gen tedavisiydi. Subkütan tedaviler ebeveynler, EHL faktörler ise hemofilikler tarafından ikinci sırada tercih edilmekteydi. Tedavi seçeneklerinin tercih edilme nedenleri değerlendirildiğinde, daha az sayıda enjeksiyon olanağı sağlamaları her üç tedavi için de en çok saptanan tercih nedeniydi. İlaç yan etki endişesi ise her üç tedavi seçeneğinde de en fazla saptanan tercih etmeme nedeniydi.

Etik: Bu çalışmanın etik kurulu alınmıştır.

Ethics committee approval had been taken.

Yazar katkı durumu; Çalışmanın konsepti; MCU, KK, dizaynı; $\mathrm{MCU}, \mathrm{KK}$, Literatür taraması; MCU, KK, verilerin toplanması ve işlenmesi; MCU, KK, istatistik; MCU, KK, yazım aşaması MCU, KK,

Author contribution status; The concept of the study; MCU, KK, design; MCU, KK, literature review; MCU, KK, collecting and processing data; MCU, KK, statistics; MCU, KK, writing phase; MCU, KK,

Yazarlar arasında çıkar çatışması yoktur.

The author declares no conflict of interest.

Finansal Destek: yoktur / Funding: none

doi: https://doi.org/10.33713/egetbd.941441

\section{KAYNAKLAR}

1. Hoyer LW. Hemophilia A. N Engl J Med 1994; 330: 38-47.

2. van Dijk K, Fischer K, van der Bom JG, et al. Variability in clinical phenotype of severe haemophilia: the role of the first joint bleed. Haemophilia 2005; 11: 438-443.

3. Srivastava A, Brewer AK, Mauser-Bunschoten EP, et al. Guidelines for the management of hemophilia. Haemophilia 2013; 19: e1-47.

4. Bolton-Maggs PH, Pasi KJ. Haemophilias A and B. Lancet 2003; 361: 1801-9.

5. Plug I, Van Der Bom JG, Peters M, Mauser-Bunschoten EP, De Goede-Bolder A, Heijnen L, et al. Mortality and causes of death in patients with hemophilia, 1992-2001: a prospective cohort study. J Thromb Haemost. 2006;4(3):510-6.

6. Plug I, van der Bom JG, Peters M, Mauser-Bunschoten EP, de Goede-Bolder A, Heijnen L, et al. Thirty years of hemophilia treatment in the Netherlands, 1972-2001. Blood. 2004;104(12):3494-500.

7. Graf L. Extended Half-Life Factor VIII and Factor IX Preparations. Transfus Med Hemother. 2018 Apr;45(2):86-91. doi: 10.1159/000488060. Epub 2018 Mar 21.

8. Franchini M, Mannucci PM. Non-factor replacement therapy for haemophilia: a current update. Blood Transfus. 2018 Sep;16(5):457-461.

9. Meeks SL, Batsuli G. Hemophilia and inhibitors: current treatment options and potential new therapeutic approaches. Hematology Am Soc Hematol Educ Program. 2016;2016:657-62.

10. Batty P, Lillicrap D. Advances and challenges for hemophilia gene therapy. Hum Mol Genet. 2019 Oct 1;28(R1):R95-R101.

11. von Mackensen S, Kalnins W, Krucker J, Weiss J, Miesbach W, Albisetti M, Pabinger I, Oldenburg J. Haemophilia patients' unmet needs and their expectations of the new extended halflife factor concentrates. Haemophilia. 2017 Jul;23(4):566-574.

12. Steen Carlsson K, Andersson E, Berntorp E. Preferencebased valuation of treatment attributes in haemophilia $A$ using web survey. Haemophilia. 2017 Nov;23(6):894-903. doi: 10.1111/hae.13322. Epub 2017 Aug 29. PMID: 28851125.

13. van Balen EC, Wesselo ML, Baker BL, Westerman MJ, Coppens M, Smit C, Driessens MHE, Leebeek FWG, van der Bom JG, Gouw SC. Patient Perspectives on Novel Treatments in Haemophilia: A Qualitative Study. Patient. 2020 Apr;13(2):201210. doi: 10.1007/s40271-019-00395-6. PMID: 31691206; PMCID: PMC7075838.

14. Balkaransingh $P$, Young $G$. Novel therapies and current clinical progress in hemophilia A. Ther Adv Hematol. 2018 Feb;9(2):49-61. doi: 10.1177/2040620717746312. Epub 2017 Dec 28. PMID: 29387330; PMCID: PMC5768270.

15. van Overbeeke E, Hauber B, Michelsen S, Peerlinck K, Lambert C, Hermans C, Lê PQ, Goldman M, Simoens S, Huys I. Patient preferences for gene therapy in haemophilia: Results from the PAVING threshold technique survey. Haemophilia. 2021 Sep 1.

16. Lock J, de Bekker-Grob EW, Urhan G, Peters M, Meijer K, Brons $\mathrm{P}$, et al. Facilitating the implementation of pharmacokineticguided dosing of prophylaxis in haemophilia care by discrete choice experiment. Haemophilia. 2016;22(1):e1-10.

17. Smit C. Personal reflections of a patient representative in an appraisal committee. Patient. 2015;8(1):5-10. 